\title{
The Efficacy of Inactivated Virus Vaccine against Viral Nervous Necrosis (VNN)
}

\author{
Hirofumi Yamashita ${ }^{1}$, Yoshiyuki Fujita ${ }^{1}$, Hidemasa Kawakami ${ }^{2}$ and Toshihiro Nakai ${ }^{3 *}$ \\ ${ }^{1}$ Ehime Prefectural Fisheries Experimental Station, Uwajima 798-0104, Japan \\ ${ }^{2}$ Ehime Prefectural Fish Disease Control Center, Uwajima 798-0087, Japan \\ ${ }^{3}$ Graduate School of Biosphere Science, Hiroshima University, \\ Higashihiroshima 739-8528, Japan
}

(Received November 18, 2004)

\begin{abstract}
The efficacy of inactivated betanodavirus as a vaccine against viral nervous necrosis (VNN) was evaluated using juvenile sevenband grouper Epinephelus septemfasciatus. Fish were intraperitoneally injected once with formalin-inactivated redspotted grouper nervous necrosis virus (RGNNV). Virus-neutralizing antibodies were detected in the vaccinated fish from Day 10 to the end of the experimental period (Day 160), showing 1:2,000 or higher mean antibody titers from Day 21 to Day 77 . The vaccinated and unvaccinated control fish were challenged by intramuscular injection with the homologous virus at 14,35 and 74 days post-vaccination. The vaccinated fish showed significantly lower mortalities at any challenges than the control fish, with the RPS (relative percent survival) values 67 or higher. A field trial, in which fish were exposed to natural infection in net pens, also resulted in higher survival rates in the vaccinated fish $(\mathrm{RPS}=85)$ during the experimental period of 9 weeks. This high induction of neutralizing antibodies and protection indicates the potential of the inactivated virus vaccine against VNN.
\end{abstract}

Key words: betanodavirus, viral nervous necrosis, viral encephalopathy and retinopathy, vaccination, Epinephelus septemfasciatus, inactivated vaccine, VNN, VER

Infections by piscine nodaviruses (Nodaviridae, Betanodavirus), named viral nervous necrosis (VNN) or viral encephalopathy and retinopathy (VER), have caused severe damages in marine aquaculture worldwide for these two decades (Muroga, 2001; Munday et al., 2002; Office International des Epizooties, 2003). The genome of the betanodaviruses consists of two ssRNAs; RNA1 (3.1 kb) encodes the viral replicase and RNA2 $(1.4 \mathrm{~kb})$ encodes the coat protein (Ball et al., 2000). Four genotypes, which are identified based on the coat protein gene sequences, have been known among betanodaviruses isolated from a variety of diseased fish; SJNNV (striped jack nervous necrosis virus) type, TPNNV (tiger puffer nervous necrosis virus) type, RGNNV (redspotted grouper nervous necrosis virus) type, and BFNNV (barfin flounder nervous necrosis virus) type (Nishizawa et al., 1997). Among them, RGNNV and genetically related viruses were commonly isolated from a variety of cultured warm-water fish species (Nishizawa et al., 1997; Iwamoto et al., 1999; Chi et

\footnotetext{
* Corresponding author

E-mail: nakaitt@ hiroshima-u.ac.jp
}

al., 2003).

Fish affected by VNN exhibit a range of neurological signs; abnormal swimming behavior and tissue vaccuolation in the central nervous system. Mass mortalities due to betanodavirus infection usually occur in fish at larval and juvenile stages, but in some cases fish are susceptible to the agent even at grow-out stages (Fukuda et al., 1996; Le Breton et al., 1997; Aspehaug et al., 1999). In Japan, particularly sevenband grouper Epinephelus septemfasciatus is highly susceptible to a betanodavirus (RGNNV) and the mortality often reaches to $50 \%$ or more even during the grow-out culture period in net pens (Tanaka et al., 1998; Tsuchihashi et al., 2002).

It was demonstrated that virus-carrying broodfish are important inoculum sources of the agent to the larvae in VNN of some fish species including sevenband grouper, and the larval mortality can be controlled by elimination of virus-carrying broodfish and disinfection of fertilized eggs and rearing water (Mori et al., 1998; Watanabe et al., 1998; Tsuchihashi et al., 2002). However, the transmission mode of betanodaviruses in fish at grow-out stages remains unknown though wild fish 
are suspected as carriers or reservoirs of the virus (Barker et al., 2002; Gomez et al., 2004), and thus it is urgently required to establish control procedures for VNN during grow-out culture.

The previous studies demonstrated that injection of Escherichia coli-expressed recombinant coat protein of betanodavirus (RGNNV and SJNNV) can induce protective immunity with neutralizing antibodies in the fish $E$. septemfasciatus, Chromileptes altivelis and Scophthalmus maximus against experimental infections (Tanaka et al., 2001; Húsgard et al., 2001; Yuasa et al., 2002), suggesting a possibility of vaccination for controlling VNN. In the present study, we investigated the efficacy of formalin-inactivated betanodavirus as a vaccine against experimentally and naturally induced VNN in sevenband grouper.

\section{Materials and Methods}

Fish

Hatchery-reared sevenband grouper (12.3 g in average body weight) were used for vaccination experiments. Fish were reared at about $20^{\circ} \mathrm{C}$ in $4 \mathrm{~m}^{3}$ tanks with a flow through system, water of which had been previously disinfected with ultraviolet (UV) light. Prior to experiments, 20 fish were randomly sampled from fish stocks and the brains and eyes were examined for betanodavirus by reverse transcriptase-polymerase chain reaction (RT-PCR) according to a previously described method (Nishizawa et al., 1994). No PCR products were detected in all fish examined.

\section{Virus and virus propagation}

A betanodavirus isolate designated as SGEhi00 strain, which had been isolated from diseased sevenband grouper in Ehime prefecture, Japan, in 2000, was used for all the experiments: vaccine preparation, immunization of fish, virus challenge tests and virus-neutralizing antibody assays. This strain was identified as RGNNV based on the sequence analysis of the coat protein gene (data not shown).

The SGEhi00 strain was propagated in E-11 cells (Iwamoto et al., 2000). The cells were grown at $25^{\circ} \mathrm{C}$ in Leibovitz L-15 medium (Gibco BRL, USA) supplemented with $10 \%$ fetal bovine serum (FBS). Monolayer cultures in a $25 \mathrm{~cm}^{2}$ flask were washed twice with Hanks' balanced salt solution (HBSS) and then inoculated with the SGEhi00 strain at a dose of $10^{6.5} \mathrm{TCID}_{50}$. After incubation with $5 \mathrm{~mL}$ of $\mathrm{L}-15$ medium ( $2 \% \mathrm{FBS}$ ) at $25^{\circ} \mathrm{C}$ for 5 days when the monolayer was heavily disintegrated, the culture fluid was centrifuged at $2,500 \times g$ for $10 \mathrm{~min}$ $\left(4^{\circ} \mathrm{C}\right)$, and stored at $-80^{\circ} \mathrm{C}$ until used. Infective titers of the virus stock were determined by a cell culture assay system with E-11 cells described previously (Iwamoto et al., 2000).
Inactivation of virus

Formalin was added to the cell culture supernatant containing the virus at $10^{9.1} \mathrm{TCID}_{50} / \mathrm{mL}$ at a final concentration of $0.01,0.1,0.5$ or $1.0 \%$. During incubation at $4^{\circ} \mathrm{C}$ for 10 days, the virus infectivity was examined by the cell culture assay. Inactivation rate of virus was calculated from the $\mathrm{TCID}_{50}$ of the untreated culture supernatant.

\section{Neutralizing antibody assay}

Fish $(n=90)$ were injected intraperitoneally with 0.1 $\mathrm{mL}$ of the culture supernatant treated with $0.5 \%$ formalin (vaccine) for 10 days. Control fish $(n=60)$ received 0.1 $\mathrm{mL}$ of HBSS. These fish were reared in $4 \mathrm{~m}^{3}$ tanks with UV-irradiated water supply at $20^{\circ} \mathrm{C}\left( \pm 0.5^{\circ} \mathrm{C}\right)$ and fed with commercial pellets once a day. At 10, 21, 30, 45, 61, $77,90,133$ and 160 days post-vaccination or at 30,61 , 90, 133 and 160 days post-inoculation of HBSS for the control, each ten fish was sacrificed to collect blood from caudal vein, and the serum samples were stored at $-20^{\circ} \mathrm{C}$ until use. Virus-neutralizing antibody titers were examined using E-11 cells and the SGEhi00 strain, as described previously (Tanaka et al., 2001). Briefly, $\mathrm{E}-11$ cells were cultured in 96-well tissue culture plates (Corning, USA) in L-15 medium (5\% FBS) prior to the assay. All fish sera were diluted with 39 volume of HBSS supplemented with penicillin $100 \mathrm{I} . \mathrm{U} . / \mathrm{mL}$ and streptomycin $100 \mu \mathrm{g} / \mathrm{mL}$ (HBSS-P/S), followed by serial 2-fold dilution with HBSS-P/S. Serum samples at each dilution were mixed with equal volume of the virus $\left(10^{1.7}\right.$ $\mathrm{TCID}_{50} / 0.025 \mathrm{~mL}$ ) and incubated at $25^{\circ} \mathrm{C}$ for $1 \mathrm{~h}$, and the mixture was inoculated into the wells. Four wells were used for each diluted sample. Cytopathic effects (CPE) were observed daily at $25^{\circ} \mathrm{C}$ for ten days and the virusneutralizing antibody titer of serum was calculated according to the method of Reed and Muench (1938).

\section{Vaccination and virus challenge}

A thousand fish were intraperitoneally injected with $0.1 \mathrm{~mL}$ of the above-mentioned vaccine $(0.5 \%$ formalintreated culture supernatant). Another 1,000 fish received $0.1 \mathrm{~mL}$ of $\mathrm{HBSS}$ as a control. Fish were transferred to $4 \mathrm{~m}^{3}$ tanks with UV-treated water supply at $20^{\circ} \mathrm{C}\left( \pm 0.5^{\circ} \mathrm{C}\right)$ and fed with commercial pellets once a day.

The effects of the vaccine were evaluated by both artificial and natural infection of betanodavirus. In artificial challenge tests, at 14, 35 and 74 days after vaccine or HBSS inoculation, vaccinated and control fish were intramuscularly injected with the SGEhiOO strain at doses of $10^{3.5}$ and $10^{4.5} \mathrm{TCID}_{50} /$ fish and observed in 120$L$ tanks at $25^{\circ} \mathrm{C}\left( \pm 0.5^{\circ} \mathrm{C}\right)$ for 15 days. All challenge tests were carried out in duplicate, each consisting of 25 fish. For natural infection, at 10 days post-immunization, fish were transferred to net pens $(3 \times 3 \times 2.5 \mathrm{~m})$ in Uwajima Bay, Ehime prefecture. Two pair net pens, 
each containing vaccinated fish $(n=150)$ and control fish $(n=150)$, were placed $15 \mathrm{~m}$ apart. The experiment started in September and terminated in November (nine weeks) in 2003. In addition, sera $(n=10)$ of the survivors of both vaccinated and control fish were tested at 64,123 and 188 days post-inoculation for the neutralizing antibody, as described above.

All dead fish, all survivors with abnormal swimming and ten survivors with normal swimming at the termination of the challenge experiments were submitted for virus isolation from the brains. The brain of fish was homogenized with 10 to 20 volume of HBSS-P/S and centrifuged $2,500 \times g$ for $10 \mathrm{~min}\left(4^{\circ} \mathrm{C}\right)$. The supernatant was passed through a $0.45 \mu \mathrm{m}$ membrane filter and $0.1 \mathrm{~mL}$ of the filtrate was inoculated in the $\mathrm{E}-11$ monolayer culture in a 24-well plate. CPEs were observed daily for ten days. Identificaton of betanodavirus was performed by indirect fluorescent antibody test using a monoclonal antibody produced against the SGEhi00 strain.

\section{Statistical analysis}

Statistical analysis was carried out using Fisher's exact probability test for fish mortalities and MannWhitney's U-test for neutralizing antibody titers. The relative percent survival (RPS; Amend, 1981) was calculated from the cumulative mortality by the following formula: RPS $=\{1-(\%$ mortality of vaccinated group $/ \%$ mortality of control group) $\} \times 100$.

\section{Results}

\section{Inactivation of virus}

More than $99.99 \%$ virus lost the infectivity within three days $\left(4^{\circ} \mathrm{C}\right)$ after treatment with 0.5 or $1.0 \%$ formalin, while inactivation rates at 0.01 and $0.1 \%$ concentrations after ten days were 90 and $99 \%$, respectively (Table 1).

Table 1. Inactivation of betanodavirus RGNNV by formalin

\begin{tabular}{llrrr}
\hline \multirow{2}{*}{$\begin{array}{l}\text { Formalin } \\
\text { conc. }(\%)\end{array}$} & \multicolumn{4}{c}{ Incubation time (days) at $4^{\circ} \mathrm{C}$} \\
\cline { 2 - 5 } & \multicolumn{1}{c}{1} & \multicolumn{1}{c}{3} & \multicolumn{1}{c}{5} & 10 \\
\hline 0 & $9.1^{*}$ & 9.1 & 8.6 & 8.6 \\
0.01 & 7.6 & 7.6 & 7.6 & 7.6 \\
0.1 & 7.6 & 6.6 & 6.6 & 6.1 \\
0.5 & 3.4 & $<3.1$ & $<3.1$ & $<3.1$ \\
1.0 & $<3.1$ & $<3.1$ & $<3.1$ & $<3.1$ \\
\hline
\end{tabular}

* $\log _{10} \mathrm{TCID}_{50} / \mathrm{mL}$

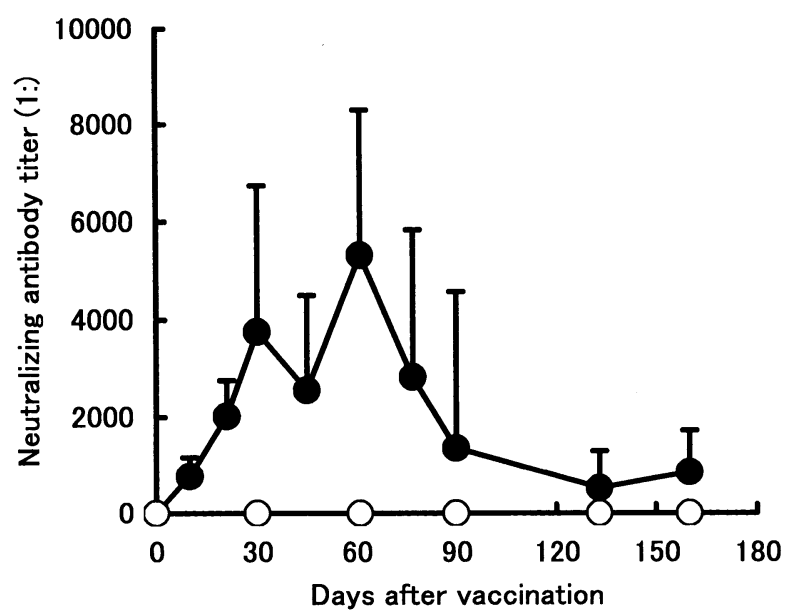

Fig. 1. Betanodavirus (RGNNV)-neutralizing antibody titers in sevenband grouper inoculated with the formalin-inactivated virus vaccine. $\bullet$ : vaccinated fish. $\bigcirc$ : unvaccinated fish. Titer 0 indicates $1: 80$ or lower.

Table 2. Vaccine efficacy against artificial nodavirus infection in sevenband grouper

\begin{tabular}{|c|c|c|c|c|c|c|c|c|c|}
\hline \multirow[t]{2}{*}{$\begin{array}{l}\text { Days after } \\
\text { vaccination }\end{array}$} & \multirow[t]{2}{*}{$\begin{array}{l}\text { Exp. } \\
\text { group }\end{array}$} & \multirow[t]{2}{*}{$\begin{array}{c}\text { Challenge } \\
\text { dose (log } \\
\text { TCID }_{50} \\
\text { /fish }\end{array}$} & \multicolumn{2}{|c|}{$\begin{array}{l}\text { No of fish died of nodavirus } \\
\text { infection / examined (\%) }\end{array}$} & \multirow[t]{2}{*}{$\begin{array}{r}\text { RPS } \\
(\%)\end{array}$} & \multicolumn{2}{|c|}{$\begin{array}{l}\text { No of survivors showing } \\
\text { clinical sign/examined } \\
(\%)\end{array}$} & \multicolumn{2}{|c|}{$\begin{array}{c}\text { No of survivors without } \\
\text { clinical sign from which } \\
\text { the virus was } \\
\text { isolated/examined (\%) }\end{array}$} \\
\hline & & & Vaccinated & Control & & Vaccinated & Control & Vaccinated & Control \\
\hline \multirow{4}{*}{14} & \multirow{2}{*}{ A } & 4.5 & $1 / 25(4.0)^{*}$ & $22 / 25$ (88.0) & 95 & $1 / 24$ & $3 / 3$ & $2 / 10$ & - \\
\hline & & 3.5 & $1 / 25(4.0)^{*}$ & $15 / 25(60.0)$ & 93 & $1 / 24$ & $2 / 10$ & $2 / 10$ & $4 / 8$ \\
\hline & \multirow{2}{*}{ B } & 4.5 & $3 / 25(12.0)^{*}$ & $19 / 25(76.0)$ & 84 & $0 / 22$ & $6 / 6$ & $2 / 10$ & - \\
\hline & & 3.5 & $0 / 25(0)^{*}$ & $19 / 25(76.0)$ & 100 & $0 / 25$ & $2 / 6$ & $2 / 10$ & $2 / 4$ \\
\hline \multirow{4}{*}{35} & \multirow{2}{*}{ C } & 4.5 & $7 / 25(28.0)^{*}$ & 23/25 (92.0) & 70 & $1 / 18$ & $2 / 2$ & $1 / 10$ & - \\
\hline & & 3.5 & $1 / 25(4.0)^{*}$ & 22/25 (88.0) & 95 & $0 / 24$ & $3 / 3$ & $1 / 10$ & $1 / 1$ \\
\hline & \multirow{2}{*}{ D } & 4.5 & $4 / 25(16.0)^{*}$ & $20 / 25(80.0)$ & 80 & $1 / 21$ & $4 / 5$ & $0 / 10$ & $0 / 1$ \\
\hline & & 3.5 & $3 / 25(12.0)^{*}$ & $22 / 25(88.0)$ & 86 & $0 / 22$ & $2 / 3$ & $2 / 10$ & $0 / 1$ \\
\hline \multirow{4}{*}{74} & \multirow[b]{2}{*}{$E$} & 4.5 & $6 / 25(24.0) *$ & $19 / 25(76.0)$ & 68 & $2 / 19$ & $0 / 6$ & $2 / 10$ & $3 / 6$ \\
\hline & & 3.5 & $5 / 24(20.8)^{* *}$ & $17 / 25(68.0)$ & 67 & $0 / 19$ & $2 / 8$ & $0 / 10$ & $2 / 6$ \\
\hline & & 4.5 & $4 / 25(16.0)^{*}$ & $24 / 25(96.0)$ & 83 & $3 / 21$ & $0 / 1$ & $2 / 10$ & $1 / 1$ \\
\hline & & 3.5 & $3 / 24(12.5)^{*}$ & $22 / 25(88.0)$ & 86 & $1 / 21$ & $1 / 3$ & $2 / 10$ & $1 / 2$ \\
\hline \multicolumn{3}{|c|}{ Average (\%) } & $38 / 298(12.8)$ & $244 / 300(81.3)$ & 84 & $10 / 260(3.8)$ & $27 / 55(49.1)$ & $18 / 120(15.0)$ & $14 / 30(46.7)$ \\
\hline
\end{tabular}

Fish were intraperitoneally injected either with formalin-inactivated vaccine (vaccinated group) or with HBSS (control group) and challenged by the intramuscular-injection with RGNNV at 14,35 , and 74 days post-immunization.

$* p<0.001 * * p<0.05$ (Fisher's exact probability test) 


\section{Virus-neutralizing antibody titers}

Throughout the experimental period of 160 days after intraperitoneal injection with formalin (0.5\%)-inactivated virus, neither mortality nor abnormal swimming behavior was found in fish. No neutralizing antibody titers were detected in the control fish group (less than $1: 80)$. In the vaccinated fish, neutralizing antibodies were detected at Day 10 with the mean titer of $1: 770$ and at $1: 2,000$ or higher mean titers from Day 21 to Day 77. Thereafter, the titers decreased but remained still detectable at Day 160 (mean 1:860) (Fig .1).

\section{Artificial infection with betanodavirus}

The results of the artificial challenge tests to vaccinated and control fish are summarized in Table 2 and the cumulative mortality of fish after the challenge is shown in Fig. 2. There was no abnormality in the vaccinated or control fish challenged with HBSS. In almost all cases challenged with virus, independent of challenge dose, the mortality in both control and vaccinated fish groups initiated at 4 days post-challenge and terminated until 10 days post-challenge (Fig. 2). The vaccinated fish groups showed significantly lower mortalities in every challenge test than the control groups $(p<0.05$ or $p<0.001$ in Fisher's exact probability test), and the RPS values were high, ranging from 67 to 100 . Viral etiology of the fish death was demonstrated except only two fish (each one of group $E$ and $F$ ), both of which darted out of tanks at 2 days post-inoculation and died. When fish were examined at the termination of the infection experiments (15 days post-inoculation), the rates of fish showing disease signs (abnormal swimming) were much
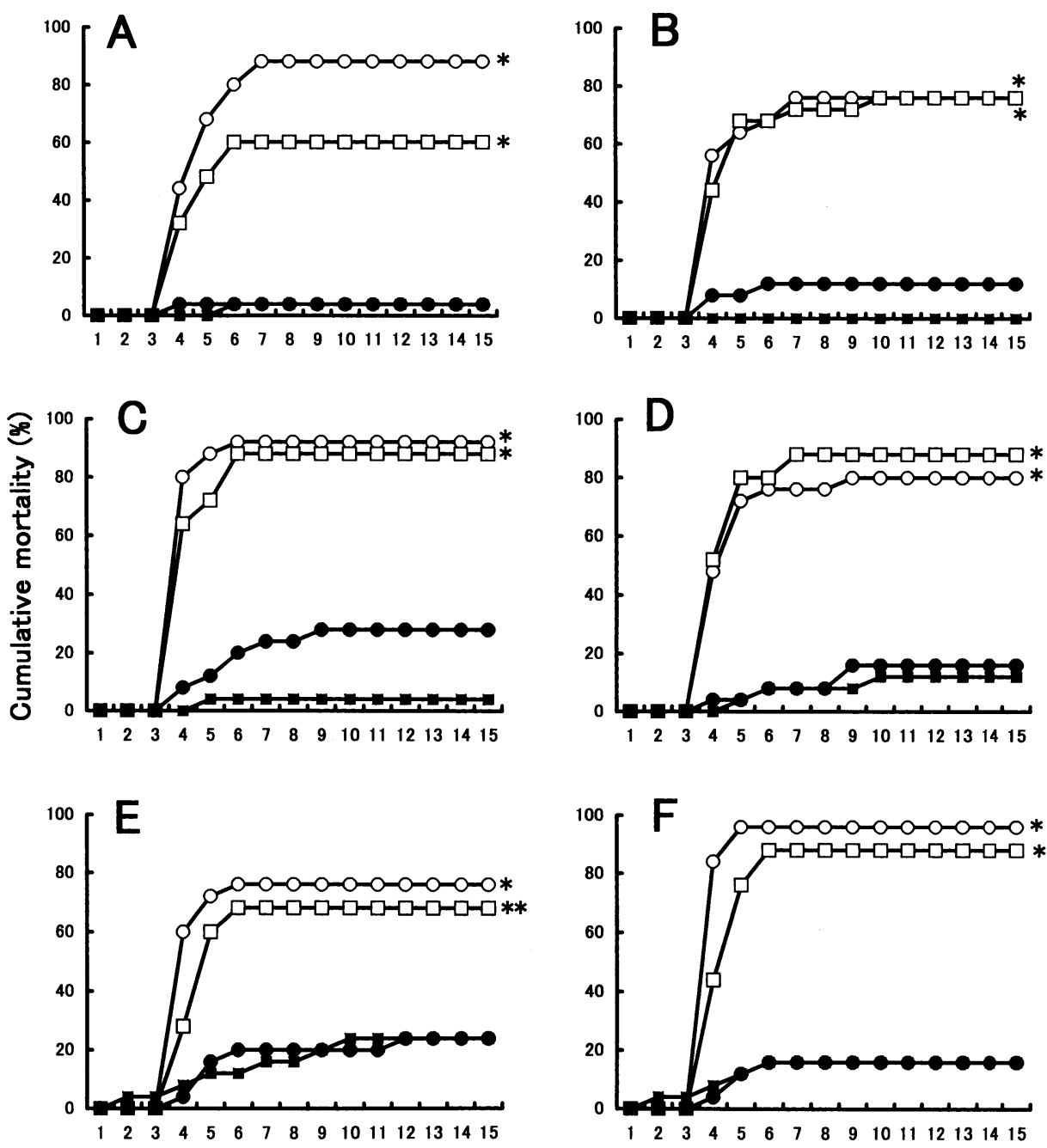

Days after virus inoculation

Fig. 2. Cumulative mortality of sevenband grouper after artificial infection with betanodavirus. Vaccinated and unvaccinated fish groups in duplicate $(n=25)$ were challenged intramuscularly with RGNNV at 14 days $(A$ and $B), 35$ days $(C$ and $D)$, and 74 days $\left(E\right.$ and $F$ ) post-immunization. $\quad$ : vaccinated and challenged with $10^{4.5} \mathrm{TCID}_{50} / \mathrm{fish}$. $\mathbf{\square}$ : vaccinated and challenged with $10^{3.5} \mathrm{TCID}_{50} /$ fish. $\bigcirc$ : unvaccinated and challenged with $10^{4.5} \mathrm{TCID}_{50} /$ fish. $\square$ : unvaccinated and challenged with $10^{3.5}$ $\mathrm{TCID}_{50} /$ fish. $* p<0.001, * * p<0.05$ (Fisher's exact probability test) 


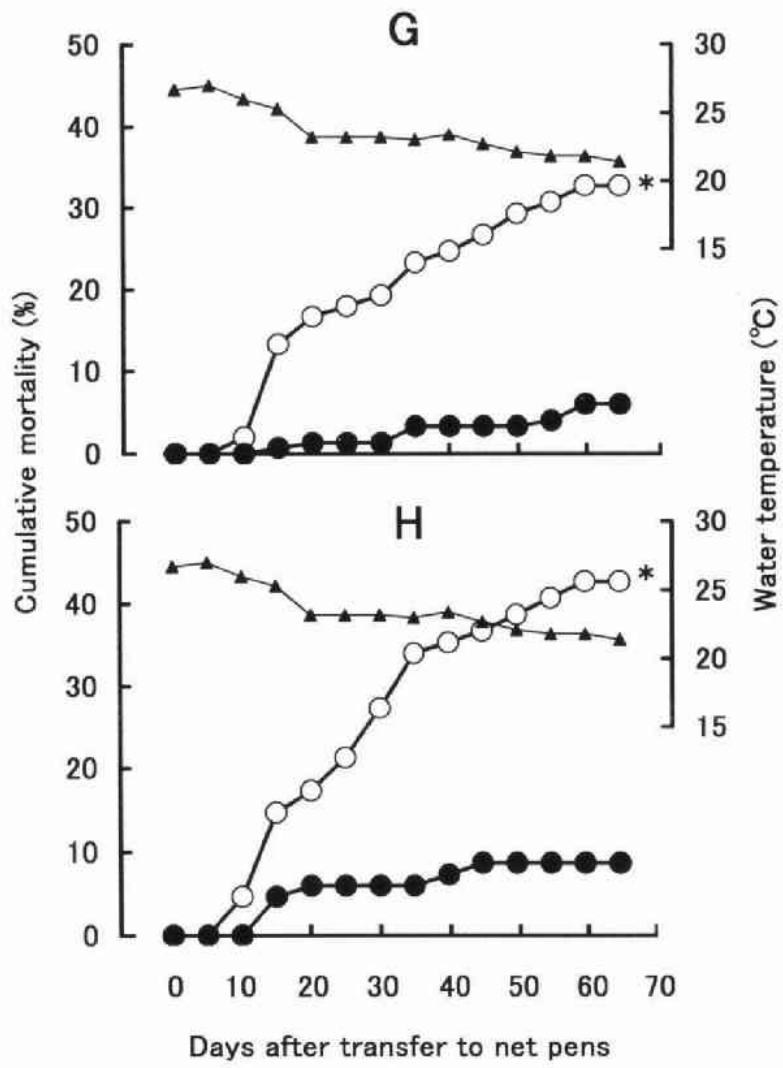

Fig. 3. Cumulative mortality of sevenband grouper during natural infection with betanodavirus. Ten days after inoculation with the formalin-inactivated vaccine (vaccinated group) or with HBSS (control group), 2 pair groups ( $G$ and $H$ ), each consisting of vaccinated fish ( $n$ $=150)$ and unvaccinated fish $(n=150)$, were transferred to net pens. : vaccinated fish 0 : unvaccinated fish $\mathbf{A}$ : water temperature. $* p<0.001$ (Fisher's exact probability test)

higher ( $49.1 \%$ in average of three challenge tests) in the control fish than those ( $3.8 \%$ in average) in the vaccinated fish. Reisolation rates of the virus in the survivors without clinical signs were also higher in the control fish (46.7\% in average) than those in the vaccinated fish (15.0\% in average) (Table 2 ).

\section{Natural infection with betanodavirus}

After fish at 10 days post-vaccination were transferred to net pens, mortality started at Day 7 and increased particularly in the control fish in both pairs (G and $\mathrm{H}$ ) until the termination of the experiment (Fig. 3). During the experimental period, water temperature ranged from $28^{\circ} \mathrm{C}$ (September) to $22^{\circ} \mathrm{C}$ (November). Betanodavirus was isolated from dead fish except 21 fish (seven in the vaccinated and 14 in the control). Specific cumulative mortality of the control fish was significantly higher than those of both vaccinated fish ( $p<$ 0.001 in Fisher's exact probability test) (Table 3 ). RPS values in $\mathrm{G}$ and $\mathrm{H}$ pairs were 83 and $87 \%$, respectively. At the termination of the experiment (Day 64), there were
Table 3. Vaccine efficacy against natural nodavirus infection in sevenband grouper

\begin{tabular}{|c|c|c|c|c|c|}
\hline \multirow[t]{2}{*}{$\begin{array}{l}\text { Fish } \\
\text { group }\end{array}$} & \multicolumn{2}{|c|}{$\begin{array}{c}\text { No of fish died of } \\
\text { nodavirus } \\
\text { infection / examined } \\
(\%)\end{array}$} & \multirow[t]{2}{*}{$\begin{array}{l}\text { RPS } \\
(\%)\end{array}$} & \multicolumn{2}{|c|}{$\begin{array}{c}\text { No of survivors from } \\
\text { which betanodavirus } \\
\text { was isolated / } \\
\text { examined }(\%)\end{array}$} \\
\hline & Vaccinated & Control & & Vaccinated & Control \\
\hline G & $7 / 148(4.7)^{*}$ & $39 / 140(27.9)$ & 83 & $1 / 10$ & $1 / 10$ \\
\hline $\mathrm{H}$ & $8 / 145(5.5)^{*}$ & $60 / 146(41.1)$ & 87 & $0 / 10$ & $2 / 10$ \\
\hline Average & $15 / 293(5.1)$ & $99 / 286(34.6)$ & 85 & $1 / 20(5.0)$ & $3 / 20(15.0)$ \\
\hline
\end{tabular}

Fish were intraperitoneally injected either with the culture supernatant treated with formalin-inactivated vaccine (vaccinated group) or with HBSS (control group) and reared in net pens for 9 weeks. $* p<0.001$ (Fisher's exact probability test)

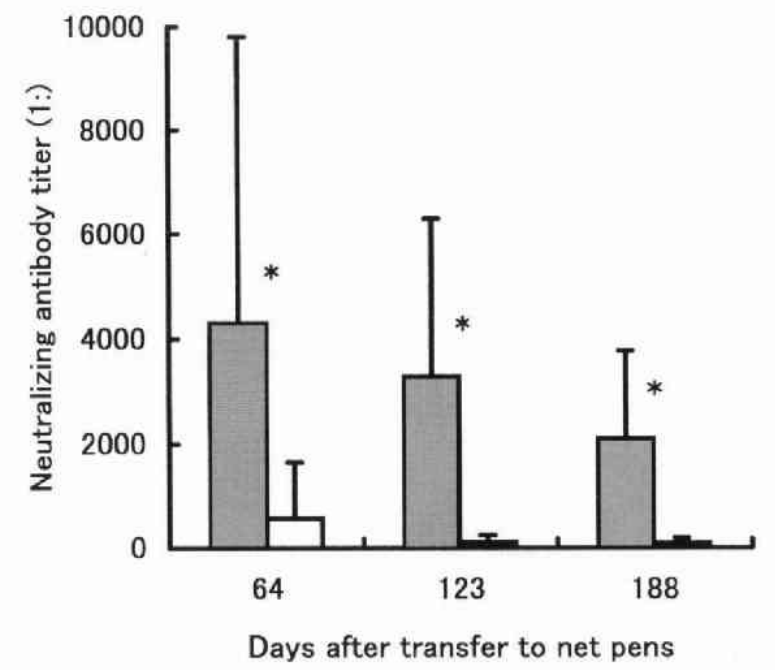

Fig. 4. Betanodavirus (RGNNV)-neutralizing antibody titers in sevenband grouper reared in net pens. Fish were inoculated with the formalin-inactivated virus vaccine (vaccinated group $\mathbf{m}$ ) or HBSS (control group $\square$ ), and 10 days later fish were transferred to net pens in Uwajima Bay. Titer 0 indicates $1: 80$ or lower. $p<$ 0.001 (Mann-Whitney's U-test).

no fish showing abnormal swimming behavior. Isolation rates of betanodavirus from the survivors were low in both control and vaccinated groups (Table 3).

The virus-neutralizing antibody at high titer levels was detected at Days 64, 123 and 188 in the survivors of the vaccinated fish and also at Day 64 in the control fish (Fig. 4). The titers in the vaccinated fish were always significantly higher than those in the control fish ( $p<$ 0.001 in Mann-Whitney's U-test).

\section{Discussion}

Killed virus vaccines, which are generally thought to be simple and safer, have been developed for some viral diseases in aquaculture (Leong and Fryer, 1993). Although a number of laboratories have attempted to 
culture piscine nodaviruses using a variety of fish cell lines since 1990, all resulted in failure, that greatly delayed research activities on the causative agent and the infection mechanisms (Munday and Nakai, 1997). However, subsequent discovery of the permissive fish cells and establishment of the culture assay system opened a new phase in virological and molecular biological studies on betanodaviruses (Munday et al., 2002). In particular, E-11 cell line (Iwamoto et al., 2000) which was derived from SSN-1 cells (Frelichs et al., 1991) made it possible to prepare the virus at $10^{9} \mathrm{TCID}_{50} / \mathrm{mL}$ or higher concentration and analyze it quantitatively, and this led to the present vaccination study with inactivated virus.

Formalin treatment is a simple method to inactivate viruses and was used in vaccine preparation for infectious pancreatic necrosis virus (IPNV), infectious hematopoietic necrosis virus (IHNV), viral hemorrhagic septicemia virus (VHSV), and red sea bream iridovirus (RSIV) infections (Dorson, 1977; Nishimura et al., 1985; de Kinkelin, 1988; Nakajima et al., 1997). The previous papers described less susceptibility of betanodaviruses against lower concentrations $(0.16 \%$ or $0.025 \%)$ of formalin (Arimoto et al., 1996; Frerichs et al., 2000). The present study demonstrated that a marked reduction in the cell infectivity of RGNNV was brought by $0.5 \%$ or higher concentration of formalin. In vivo safety of the formalin-inactivated virions was verified by the fact that intraperitoneal injection of the inactivated virus in sevenband grouper produced neither behavioral abnormality nor infectious virions in the brain, a major target organ of betanodaviruses (data not shown).

As cited before, Tanaka et al. (2001) reported that young sevenband grouper intramuscularly injected twice with the recombinant coat protein exhibited high protection (RPS $=69$ to 88 ) against the experimental challenge at $10^{3.4} \mathrm{TCID}_{50} / \mathrm{mL}$ of the homologous virus but not at $10^{4.4} \mathrm{TCID}_{50} / \mathrm{mL}$ or higher dose (RPS $=35$ to 37 ), when the artificially challenged at 20 days post-immunization. The present vaccination study with a single injection of the inactivated virus proved high protection (RPS $=67$ to 100) against the experimental challenge at $10^{4.5} \mathrm{TCID}_{50} /$ $\mathrm{mL}$ when challenged at 14,35 or 74 days postimmunization. Furthermore, a single administration of the vaccine was also highly effective $(\mathrm{RPS}=85$ ) against betanodavirus infection under a natural condition. Neutralizing-antibody production after immunization with the inactivated virus lasted longer than 160 days under a laboratory condition, as is in case of the recombinant coat protein (Tanaka et al., 2001). Considering that VNN of sevenband grouper frequently occurs in summer (July, August and September) when rearing water temperature reached to $25^{\circ} \mathrm{C}$ or higher (Fukuda et al., 1996), this duration time of immunity, either by recombinant protein or inactivated virus vaccine, is long enough to protect fish from natural infection. Furthermore, neutraliz- ing antibodies at remarkably high levels were detected in sevenband grouper reared in net pens for about 200 days after vaccine inoculation. This prolonged high antibody production may have been brought by natural infection of betanodavirus.

In addition to severe outbreaks of VNN in summer, sevenband grouper juveniles produced in land tanks of hacheries in late summer are often affected by VNN a few weeks after transfer to net pens in open sea. We recently reported that betanodaviruses were detected at high frequency by PCR-based methods from a variety of apparently healthy wild fish living around marine aquaculture areas, suggesting that aquaculture environments are heavily contaminated with betanodaviruses shed from these inapparently infected wild fish (Gomez et al., 2004). Therefore, vaccination of hatchery-produced juveniles or imported seedlings prior to transfer to net pens and also older fish at early summer will be essential to protect natural infection.

Presently, betanodavirus infections are known to 30 or more fish species in the world (Muroga, 2001; Munday et al., 2002). As groupers are highly susceptible to betanodaviruses even at young to adult stages in particular, successful commercial culture of groupers in open sea is not expected without development of vaccination system. Betanodavirus isolates from groupers all belong to a single genotype, i.e. RGNNV genotype (Nishizawa et al., 1997; Iwamoto et al., 1999; Chi et al., 2003). Mori et al. (2003) reported that betanodaviruses were divided into three serotypes $(A, B, C)$, and this sero-grouping is in part consistent with their genotypes, i.e. serotype A for SJNNV genotype, serotype B for TPNNV genotype and serotype $C$ for both RGNNV and BFNNV genotypes. This suggests that mono-valent vaccine is expected to be efficacious for VNN in groupers. However, cross-challenge experiments against fish immunized with vaccines constructed from different serotypes will be required for the future development of VNN vaccine.

Compared with the previously reported recombinant vaccine for VNN (Tanaka et al., 2001), the present inactivated virus vaccine is preferable in the following points. First, a single administration of the vaccine is expected to induce high protection with high production of neutralizing antibodies. Second, the inactivated vaccine confers the difficulty in practical administration of the recombinant protein expressed in $E$. coli, that is, its rapid autoaggregation. Finally, the inactivated vaccine may be advantageous for licensing.

\section{Acknowledgements}

This study was supported in part by a special grant from the Fisheries Agency of Japan and a Grant-in-Aid for Scientific Research (No. 16380132) from the Ministry of Education, Science, Sports and Culture of Japan. 


\section{References}

Amend, D. F. (1981): Potency testing of fish vaccines. Dev. Biol. Standard., 49, 447-454.

Arimoto, M., J. Sato, K. Mimura, K. Maruyama and I. Furusawa (1996): Effect of chemical and physical treatments on the inactivation of striped jack nervous necrosis virus (SJNNV). Aquaculture, 143, 15-22.

Aspehaug, V., M. Devold and A. Nylund (1999): The phylogenetic relationship of nervous necrosis virus from halibut (Hippoglossus hippoglossus). Bull. Eur. Ass. Fish Pathol., 19, 196-202.

Ball, L. A., D. A. Hendry, J.E. Johnson, R. R. Rueckert and P. D. Scotti (2000): Family Nodaviridae. In: Virus Taxonomy. Seventh Report of the International Committee on Taxonomy of Viruses (ed. by M. H. V. Van Regenmortel, C. M. Fauquet, D. H. L. Bishop, E. B. Carstens, M.K. Estes, S. M. Lemon, J. Manillof, M. A. Mayo, D. J. McGeoch, C. R. Pringle, R. B. Wickner), pp. 747-755. Academic Press, New York.

Barker, D. E., A.M. MacKinnon, L. Boston, M. D. B. Burt, D. K. Cone, D. J. Speare, S. Griffiths, M. Cook, R. Ritchie and G. Olivier (2002): First report of piscine nodavirus infecting wild winter flounder Pleuronectes americanus in Passamaquoddy Bay, New Brunswick, Canada. Dis. Aquat. Org., 49, 99-105.

Chi, S. C., J. R. Shieh and S. J. Lin (2003): Genetic and antigenic analysis of betanodaviruses isolated from aquatic organisms in Taiwan. Dis. Aquat. Org., 55, 221-228.

de Kinkelin, P. (1988): Vaccination against viral haemorrhagic septicaemia. In: Fish vaccination (ed. by A. E. Ellis), pp. 172-192. Academic Press, London.

Dorson, M. (1977): Vaccination trials of rainbow trout fry against infectious pancreatic necrosis. Bull. Off. Int. Epiz., 87, 405-406.

Frerichs, G. N., D. Morgan, D. Hart, C. Skerrow, R. J. Roberts and D. E. Onions (1991): Spontaneously productive C-type retrovirus infection fish cell lines. J. Gen. Virol., 72, 25372539.

Frerichs, G. N., A. Tweedie, W. G. Starkey and R. H. Richards (2000): Temperature, $\mathrm{pH}$, and electrolyte sensitivity, and heat, UV and disinfection inactivation of sea bass (Dicentrachus labrax) neuropathy virus. Aquaculture, 185, 13-24.

Fukuda, Y., H. D. Nguyen, M. Furuhashi and T. Nakai (1996): Mass mortality of cultured sevenband grouper, Epinephelus septemfasciatus, associated with viral nervous necrosis. Fish Pathol., 31, 165-170.

Gomez, D. K., J. Sato, K. Mushiake, T. Isshiki, Y. Okinaka and T. Nakai (2004): PCR-based detection of betanodaviruses from cultured and wild marine fish with no clinical signs. J. Fish Dis., 27, 603-608.

Húsgarð, S., S. Grotmol, B.K. Hjeltnes, O. M. Rødseth and E. Biering (2001): Immune response to a recombinant capsid protein of striped jack nervous necrosis virus (SJNNV) in turbot Scophathalmus maximus and Atlantic halibut Hippoglossus hippoglossus and evaluation of vaccine against SJNNV. Dis. Aquat. Org., 45, 33-44.

Iwamoto, T., K. Mori, M. Arimoto and T. Nakai (1999): High permissivity of the fish cell line $\mathrm{SSN}-1$ for piscine nodaviruses. Dis. Aquat. Org., 39, 37-47.

Iwamoto, T., T. Nakai, K. Mori, M. Arimoto and I. Furusawa (2000): Cloning of the fish cell line SSN-1 for piscine nodaviruses. Dis. Aquat. Org., 43, 81-89.
Le Breton, A., L. Grisez, J. Sweetman and F. Ollevier (1997): Viral nervous necrosis (VNN) associated with mass mortalities in cage-reared seabass, Dicentrarchus labrax (L.). J. Fish Dis., 20, 145-151.

Leong, J. C. and J. L. Fryer (1993): Viral vaccines for aquaculture. Ann. Rev. Fish Dis., 3, 225-240.

Mori, K., K. Mushiake and M. Arimoto (1998): Control measures for viral nervous necrosis of striped jack. Fish Pathol., 33, 443-444.

Mori, K., T. Mangyoku, T. Iwamoto, M. Arimoto, S. Tanaka and T. Nakai (2003): Serological relationships among genotypic variants of betanodavirus. Dis. Aquat. Org., 57, 19-26.

Munday, B. L and T. Nakai (1997): Special topic review. nodaviruses as pathogens in larval and juvenile marine finfish. World J. Microbiol. Biotechnol., 13, 375-381.

Munday, B. L., J. Kwang and N. Moody (2002): Batanodavirus infections of teleost fish: a review. J. Fish Dis., 25, 127142.

Muroga, K. (2001): Viral and bacterial diseases of marine fish and shellfish in Japanese hatcheries. Aquaculture, 202, 23-44.

Nakajima, K., Y. Maeno, J. Kurita and Y. Inui (1997): Vaccination against red sea bream iridovirus disease in red sea bream. Fish Pathol., 32, 205-209.

Nishimura, T., H. Sasaki, M. Ushiyama, K. Inoue, Y. Suzuki, F. Ikeya, M. Tanaka, H. Suzuki, M. Kohara, M. Arai, N. Shima and T. Sano (1985): A trial of vaccination against rainbow trout fry with formalin killed IHN virus. Fish Pathol., 20, $435-443$.

Nishizawa, T., K. Mori, T. Nakai, I. Furusawa and K. Muroga (1994): Polymerase chain reaction (PCR) amplification of RNA of striped jack nervous necrosis virus (SJNNV). Dis. Aquat.Org., 18, 103-107.

Nishizawa, T., M. Furuhashi, T. Nagai, T. Nakai and K. Muroga (1997): Genomic classification of fish nodaviruses by molecular phylogetic analysis of coat protein gene. Appl. Environ. Microbiol., 63, 1633-1636.

Office International des Epizooties OIE (2003): Viral encephalopathy and retinopathy. In: Manual of Diagnostic Tests for Aquatic Animals, pp. 135-141. OIE, Paris.

Reed, L. J. and H. Muench (1938): A simple method of estimating fifty percent end points. Am. J. Hyg. 27, 493-497.

Tanaka, S., H. Aoki and T. Nakai (1998): Pathogenicity of the nodavirus detected from diseased sevenband grouper Epinephelus septemfasciatus. Fish Pathol., 33, 31-36.

Tanaka, S., K. Mori, M. Arimoto, T. Iwamoto and T. Nakai (2001): Protective immunity of sevenband grouper, Epinephelus septemfasciatus Thunberg, against experimental viral nervous necrosis. J. Fish Dis., 24, 15-22.

Tsuchihashi, Y., I. Kuriyama, Y. Kuromiya, M. Kashiwagi and M. Yoshioka (2002): Control of viral nervous necrosis (VNN) in seedling production of sevenband grouper, Epinephelus septemfasciatus. Suisanzoshoku, 50, 355-361. (in Japanese with English abstract)

Watanabe, K., S. Suzuki, T. Nishizawa, K. Suzuki, M. Yoshimizu and Y. Ezura (1998): Control strategy for viral nervous necrosis of barfin flounder. Fish Pathol., 33, $445-446$.

Yuasa, K., I. Koesharyani, D. Roza, K. Mori, M. Katata and T. Nakai (2002): Immune response of humpback grouper, Cromileptes altivelis (Valenciennes) injected with the recombinant coat protein of batanodavirus. J. Fish Dis., 25, $53-56$. 